\title{
The role of age in treatment-related adverse events in patients with head and neck cancer: A systematic review
}

\author{
Andrés Coca-Pelaz MD, $\mathrm{PhD}^{1}$ (D) । Gyorgy B. Halmos $\mathrm{MD}, \mathrm{PhD}^{2}$ (1) । Primož Strojan $\mathrm{MD}, \mathrm{PhD}^{3}$ (1) । \\ Remco de Bree MD, $\mathrm{PhD}^{4}$ (D) । Paolo Bossi MD ${ }^{5}$ (D) | Carol R. Bradford $\mathrm{MD}^{6}$ (D) । \\ Alessandra Rinaldo MD, FRCSEd ad hominem, FRCS (Eng, Ir) ad eundem, FRCSGlasg, FACS ${ }^{7}$ (1) । \\ Vincent Vander Poorten MD, $\mathrm{PhD}^{8}$ (i) । Alvaro Sanabria MD, $\mathrm{PhD}^{9}$ (1) | Robert P. Takes MD, $\mathrm{PhD}^{10}$ (i) । \\ Alfio Ferlito MD, DLO, DPath, FRCSEd ad hominem, FRCS (Eng, Glasg, Ir) ad eundem, FDSRCS ad \\ eundem, FACS, FHKCORL, FRCPath, FASCP, IFCAP ${ }^{11}$ (D)
}

\footnotetext{
${ }^{1}$ Department of Otolaryngology, Hospital Universitario Central de Asturias, Oviedo, Spain

${ }^{2}$ Department of Otorhinolaryngology - Head and Neck Surgery, University of Groningen, University Medical Center Groningen, Groningen, The Netherlands

${ }^{3}$ Department of Radiation Oncology, Institute of Oncology, Ljubljana, Slovenia

${ }^{4}$ Department of Head and Neck Surgical Oncology, UMC Utrecht Cancer Center, University Medical Center Utrecht, Utrecht, The Netherlands

${ }^{5}$ Medical Oncology, Department of Medical and Surgical Specialties, Radiological Sciencesand Public HealthUniversity of Brescia, ASST-Spedali Civili, Brescia, Italy

${ }^{6}$ Department of Otolaryngology - Head and Neck Surgery, University of Michigan, Ann Arbor, Michigan

${ }^{7}$ University of Udine School of Medicine, Udine, Italy

${ }^{8}$ Otorhinolaryngology - Head and Neck Surgery and Department of Oncology, Section Head and Neck Oncology, University Hospitals Leuven, KU Leuven, Leuven, Belgium

${ }^{9}$ Department of Surgery, School of Medicine, Universidad de Antioquia, Clínica Vida, Medellín, Colombia

${ }^{10}$ Department of Otolaryngology - Head and Neck Surgery, Radboud University Medical Center, Nijmegen, The Netherlands

${ }^{11}$ International Head and Neck Scientific Group, Padua, Italy
}

\section{Correspondence}

Andrés Coca-Pelaz, Department of

Otolaryngology, Hospital Universitario Central de

Asturias, Avenida de Roma s/n - 33011 Oviedo,

Spain.

Email: acocapelaz@yahoo.es

Section Editor: David Eisele

\begin{abstract}
Head and neck squamous cell carcinoma (HNSCC) is often diagnosed in advanced stage and therefore requires aggressive, multimodal treatment. Elderly patients are often excluded from standard therapy regimens purely based on age. This clinical review aims to collect all published data in the literature on treatment modality selection in elderly patients and on age-related adverse events following treatment of HNSCC. We performed a literature search for articles on the treatment of HNSCC in elderly patients. Most of the articles were retrospective studies with the consequent limitations. It can be concluded that age is not an absolute contraindication for intensive treatment and comorbidity is an important predictor of outcome, but not the only one. Despite the existence of multiple tools for pretreatment evaluation, there are not consistent data on their use.
\end{abstract}

\section{KEYWORDS}

adverse events, comorbidity, elderly, head and neck cancer, postoperative complications, prognosis, toxicity 


\section{1 | INTRODUCTION}

Despite the increase of a subpopulation of relatively younger head and neck squamous cell cancer (HNSCC) patients with human papillomavirus (HPV) related oropharyngeal cancer patients, HNSCC remains primarily a cancer of an older population. According to the Surveillance, Epidemiology, and End Results (SEER) database, approximately $64 \%$ of all patients diagnosed with HNSCC in the United States between 1975 and 2014 were $\geq 65$ years. ${ }^{1}$ It has been estimated that $24 \%$ of newly diagnosed HNSCC patients are older than 70 years ${ }^{2,3}$ and the larynx, oropharynx, and oral cavity are the three tumor sites most common affected. ${ }^{4}$ The definition of "elderly" is not uniform and different cut points are used for this purpose. However, the National Institute on Aging suggest categories of "young old" (65-74 years), "older old" (75-85 years), and "oldest old" (>85 years). ${ }^{5}$ The majority of patients with HNSCC present with advanced stage disease which usually requires extensive combined treatment, that is, surgery and postoperative radiotherapy (RT) with or without $\mathrm{CT}$ or primary RT with or without systemic therapy (CT or cetuximab) with salvage surgery, when needed and possible. ${ }^{6}$ These intensive multimodality treatments harbor a high risk of associated acute and long-term toxicity, which in many cases is demonstrated by poor adherence to treatments, inferior quality of life (QoL), treatment-induced death, and limited life expectancy. ${ }^{7}$ In elderly patients, medical comorbidities are common. As such, these patients are considered poor candidates for intensive multimodal therapy and frequently they receive less effective but better tolerated treatments regimens, often with a poorer response. ${ }^{8}$ The selection of patients for either standard or nonstandard therapy is not clearly defined, and a comprehensive geriatric evaluation is rarely conducted. Fear of adverse events in these elderly patients often results in different treatment of elderly as compared to younger patients. An adverse event can be defined as any unfavorable and unintended sign, symptom, or disease temporally associated with the use of a medical treatment or procedure that may or may not be considered related to the medical treatment or procedure, ${ }^{9}$ thus, subjective factors frequently influence the decision on treatment. ${ }^{10}$ In the last years, the concept of frailty has been developed. The term frailty refers to a state of decreased physiological reserves, arising from cumulative deficits in several physiological systems and resulting in a diminished resistance to stressors. ${ }^{11,12}$ Research has been conducted to find screening methods to identify fit older patients who are able to receive standard cancer treatment, and vulnerable patients who should subsequently receive a geriatric assessment to guide tailoring of their treatment. ${ }^{13}$ Moreover, elderly patients are frequently not included in prospective clinical trials. These trials often accrue younger and healthier patients, as described by Siddiqui and Gwede. ${ }^{14}$ They found that the median age of the patients enrolled was between 53 and 62 years old and most studies lack data on comorbidities. Therefore, recommendations derived from these trials and guidelines based on their results are not directly applicable to older patients. Another factor is the reluctance of physicians to offer the best available therapy, based on the belief that older people are not fit to receive complex surgical procedures or intense chemoradiotherapy (CRT) ${ }^{15}$

The purpose of this article is to review the currently available literature with focus on (1) the importance of age in the treatment selection for HNSCC, (2) if these patients legitimately receive nonstandard treatment regimens, (3) if elderly HNSCC patients more often face treatment-related adverse events and worse survival in contrast to their younger counterparts and finally, and (4) if in the published articles any screening method is used to assess if older patients are candidates for standard treatment.

For this purpose, the Preferred Reporting Items for Systematic Review and Meta-Analyses were used to conduct a systematic review of the current literature. ${ }^{16}$ The search strategy aimed to include all articles concerning the treatment of HNSCC in elderly patients. A PubMed internet search updated to July 24, 2018 was performed for English language publications between the years 1980 and 2018 using the following search criteria in the title or abstract: "head and neck cancer," coupled with "older," "elderly" or "age," and "radiotherapy," "chemotherapy," "systemic therapy," "targeted therapy," "surgery," and "adverse event." The search results were reviewed for potentially eligible studies. When there was reference in the abstract that the study includes patients over 65 years old, the full text article was searched; all review articles were also checked in full. References from any full text articles were cross-checked to ensure inclusion of all relevant publications in this review (Figure 1). Studies were selected if they met the following inclusion criteria: (1) patients treated for HNSCC, (2) age of the patients $\geq 65$ years, (3) type of treatment that the patients received, (4) data about the primary site of the tumor, and (5) if the study included also younger patients, data should be analyzed by age group (eg, $>65$ years, $<65$ years). Studies involving patients of all ages, without age differentiation, were excluded.

According to our search criteria, 2543 papers were initially identified. After sorting and removal of duplicates, 82 papers that fully fit our inclusion criteria were retrieved, reviewed in detail, and summarized in Tables 1-4 according to the modality of treatment used: RT, systemic therapy (CT or targeted therapy), surgery, or multimodal therapy., ${ }^{4,15-96}$

\section{I ADVERSE EVENTS AND SURVIVAL AFTER DIFFERENT TREATMENT MODALITIES IN ELDERLY}

\section{1 | Radiotherapy}

\subsection{1 | Toxicity}

Most studies find no age-specific differences in the efficacy of radiation therapy, ${ }^{4,17}$ and note comparable survival outcome. 


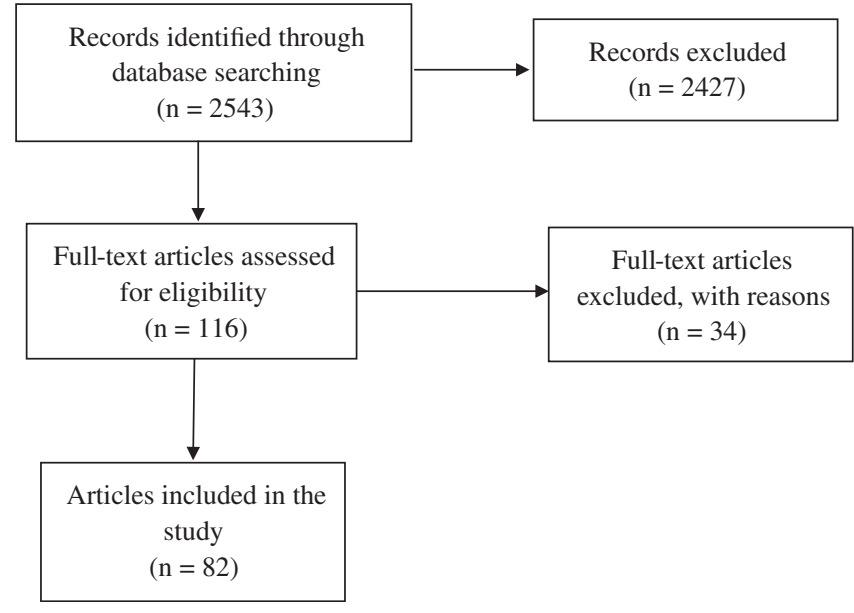

FIGURE 1 Flowchart showing the process of the study selection for the systematic review

However, the data on treatment-related toxicity differ among studies. For instance, Pignon et al ${ }^{4}$ found more severe but not more frequent acute toxicities in aged patients, and contradictory to this, Schofield et $\mathrm{al}^{21}$ found no differences. The study by Allal et $\mathrm{al}^{20}$ indicates the lack of compliance of elderly patients to accelerated radiotherapy.

\subsection{2 | Specific RT techniques}

Specific RT techniques and protocols, such as intensity modulated radiotherapy (IMRT), ${ }^{22,25}$ intensity modulated radiotherapy/image guided radiotherapy simultaneous integrated boost (IMRT/IGRT SIB), ${ }^{23}$ and hypofractionation, ${ }^{24}$ seem to be feasible and well-tolerated in elderly. Based on the published literature, age itself seems not to be a limiting factor in curative radical RT, even in the octogenarian ${ }^{18}$ and nonagenarians. ${ }^{19}$ However, data on efficacy, toxicity, and compliance in the very old patients is based on small study populations. In addition, the proportion of older patients in these trials is lower compared to the fraction they represent among all HNSCC patients, which implies a significant selection bias. Despite only apparently "fit elderly" (individuals, over 65 years of age, living independently at home or in sheltered accommodation ${ }^{97}$ ) patients are recruited to curative-intent radiotherapy programs, the meta-analysis of prospective randomized trials comparing conventional and altered fractionated radiotherapy showed a decreasing effect (worse overall survival, but not the disease-specific survival) of intensified radiotherapy regimens with increasing effect. ${ }^{98,99}$ Increase in non-cancer-related deaths and lower compliance and tolerance were recognized as possible factors for this observation. ${ }^{100,101}$ However, the difference between chronological and biological age of the patients, the parameter that was not addressed in the meta-analysis, could also play a role. ${ }^{10}$

Based on the presented data, it appears that altered fractionated radiotherapy has a decreased benefit in older patients and in patients with poor performance status. It could be due to an excess of non-cancer-related deaths but also by lower compliance and tolerance in older patients; although late toxicity and outcomes are not different, asking for careful selection of elderly patients for curative intent radiotherapy regimens.

\subsection{Chemotherapy and other systemic therapy}

\subsection{1 | Chemoradiation, bioradiation}

Adding CT to radiation therapy for the treatment of HNSCC in elderly patients is often discarded from treatment protocols, based on a meta-analysis of Pignon et al in 2009 (MACH-HN) ${ }^{102}$ This study concluded that adding CT to conventional RT has no beneficial effect in patients over 70 . There are several points of criticisms on this conclusion; one of these is the fact that non-cancer-related deaths were more common in the elderly and significantly altered the analysis. A similar observation was made by Machtay et al, ${ }^{57}$ who analyzed three RTOG chemoradiation trials (12\% of patients were over 70) for the factors influencing the occurrence of severe (grade 3-4) late toxicities with potential detrimental effect to survival: the risk of their development was significantly increased with higher age (hazard ration 1.05 per year). Another limitation of the MACH-HN study is the small number (356 patients) of elderly patients who received CRT, compared to the whole study population, which was over 17000 patients.

A more recent addition to systemic HNSCC treatment is cetuximab, a monoclonal antibody directed against the epidermal growth factor receptor, approved in 2006 for concurrent use with radiation in locally or regionally advanced disease $\mathrm{e}^{81}$ was demonstrated not to increase common acute radiationassociated toxicity or a decline of patient's QoL. ${ }^{103}$ However, in older patients ( $\geq 65$ years), no overall survival benefit was reported when used in combination with RT. ${ }^{104}$

\subsection{2 | Systemic therapy for recurrent/metastatic (RM) disease}

In the EXTREME trial, which stated the superiority of cetuximab added to platinum and 5-fluorouracil (PF) in comparison to $\mathrm{PF}$ alone in first-line setting for RM HNSCC, only $18 \%$ of the patients were 65 years and older. ${ }^{28}$ The highest benefit in survival for the three-drug regimen was observed in patients with $<65$ years (HR 0.74; 0.59-0.94), whereas it was not significant in older patients (HR 1.07; 0.65-1.77). Gebbia et $\mathrm{al}^{26}$ showed that fit elderly can receive CT without major age-related toxicity, underlining the importance of screening. The outcome of a phase III open-label trial was consistent with this study, and the results showed that advanced age does not adversely affect toxicity and oncologic outcome in patients treated in a second-line setting with afatinib or methotrexate. ${ }^{29}$ In contrast to these two studies, Argiris et $\mathrm{al}^{27}$ found significantly higher toxicity rates and also higher CT-related deaths in elderly; however, global survival data of elderly were comparable to the younger patients. These data are based on the analysis of two 


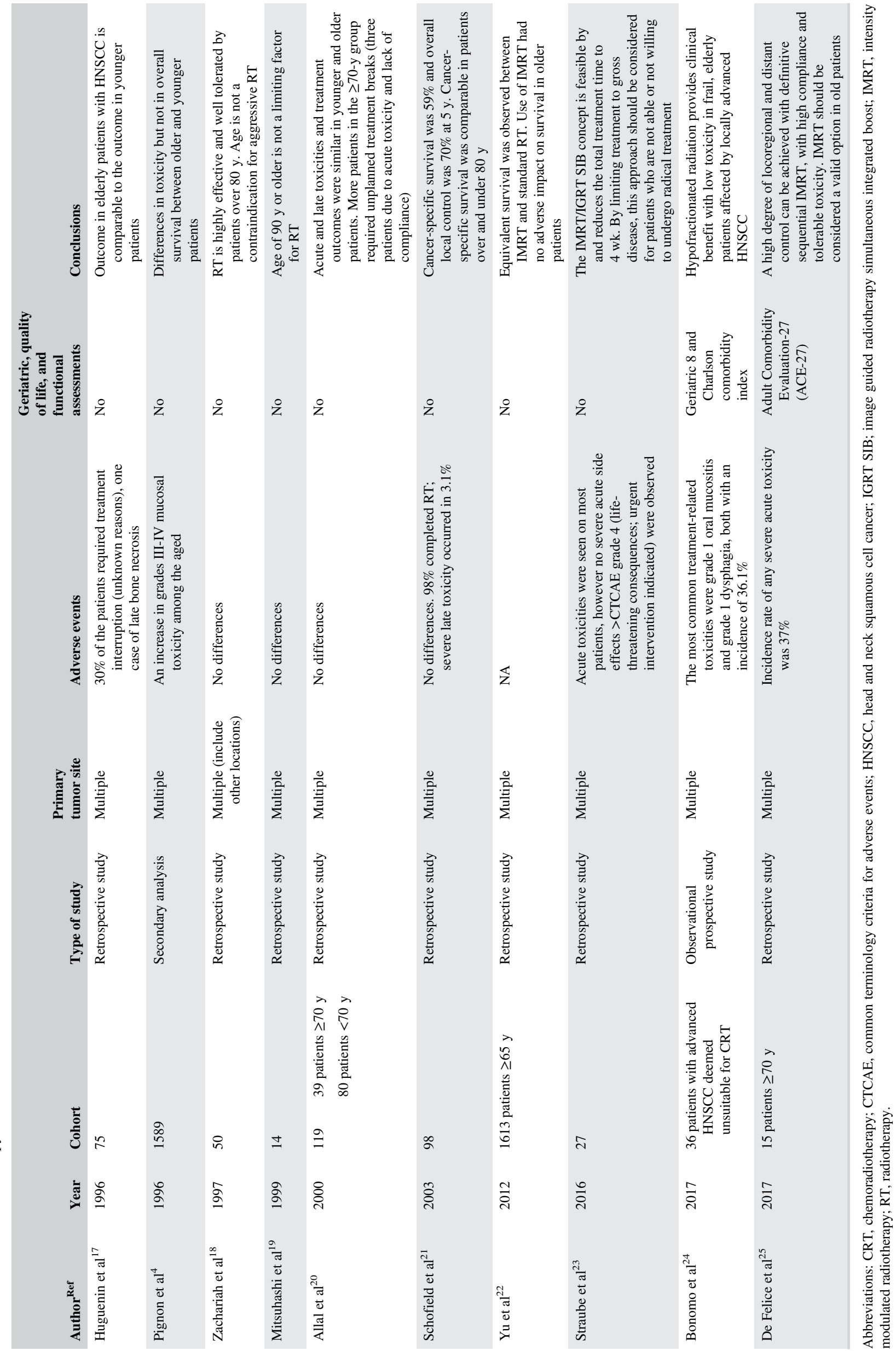




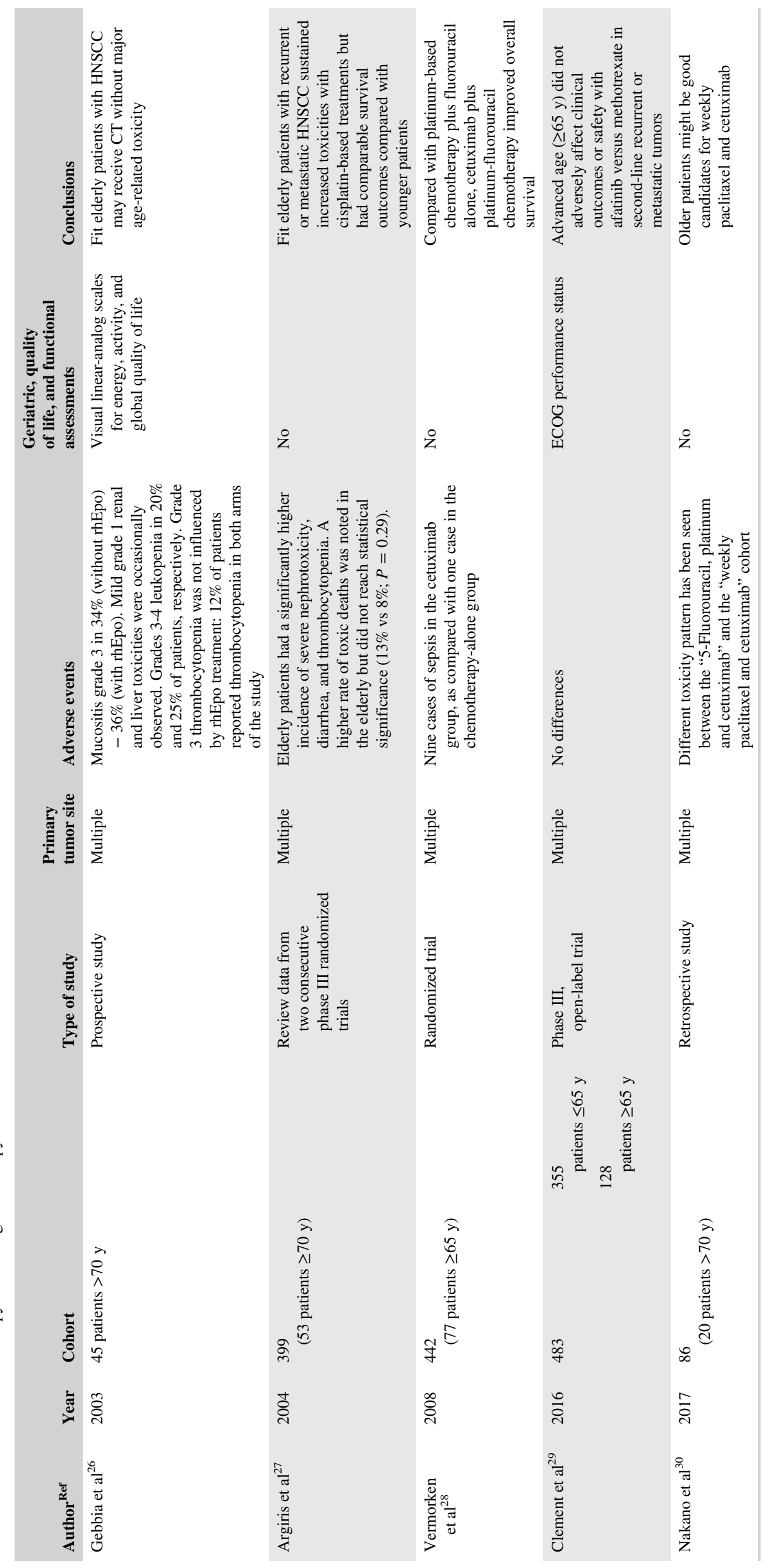


phase III Eastern Cooperative Oncology Group (ECOG) studies on palliative cisplatin-based studies with only $13 \%$ of the patients from $\geq 70$ age group. Observed differences are very likely due to the differences in eligibility for receiving CT across different age groups, indicating a need for more effective strategies for decreasing toxicities in elderly patients.

Nakano et al ${ }^{30}$ compared the efficacy of two cetuximabcontaining regimens (weekly paclitaxel and cetuximab vs PF, platinum, and cetuximab). They found that male, older age ( $\geq 70$ years), good performance status, no history of platinum chemotherapy, and the presence of a tracheostomy were favorable factors within the cohort treated with weekly paclitaxel and cetuximab.

Obviously, age-related changes in physiology of different organs alter pharmacokinetics and pharmacodynamics of systemic drugs, which increase susceptibility of normal tissues to toxicity. Changes in toxicity profile observed in older patients reduce tolerability to systemic therapies and require more effective supportive care measures; in this regard, the importance of tools for prediction of the risk of toxicity and the probability of response before administering systemic therapies should be underlined. ${ }^{27}$

\section{3 | Surgery}

The literature on the effect of age on treatment-related adverse events in patients undergoing major head and neck surgery is very consistent. However, all available literature data are based on retrospective studies, which very likely introduce selection bias in the inclusion of patients in these studies. Surgical candidates are usually thoroughly screened before major oncological head and neck surgery and only fit elderly patients are selected for these complex procedures. Usually, patients who are excluded are not analyzed, and their outcome is unknown. Therefore, these studies have to be carefully interpreted.

Roughly, two types of studies can be identified in this topic; studies comparing young vs elderly and studies including only aged patients. All studies that compare complication rates ${ }^{31-35,37,40-43,105}$ conclude that complication rate is comparable in elderly and young patients, except the study of Morgan et al. ${ }^{31}$ Despite the fact that the latter study finds slightly more frequent complications in elderly patients $(32 \%$ vs $21 \%$ ), the authors concluded that age alone should not be a factor to exclude patients from extensive surgery. ${ }^{31}$ Retrospective studies with cohorts of elderly patients that lack a control group ${ }^{34,36,38,39,44,45}$ draw the same conclusions; surgical treatment can be safely performed in elderly HNSCC patients and selection should be based on medical assessment, and not on age. Although most of the studies focused on complication rates, a small subset does report survival data. ${ }^{35}$ Interestingly, Clayman et $\mathrm{al}^{35}$ found lower local control and disease-specific survival in octogenarians when compared with group of similar patients aged up to 65 years.

\section{4 | Multimodality treatment}

The literature on age-specific treatment outcome after multimodality treatment is not very consistent. Several studies confirm no age-related differences after multimodal treatment of HNSCC in terms of treatmentrelated adverse events. ${ }^{46,47,49,60,62-64,68,77,106}$ In contrast, other studies identified more adverse events in the elderly. ${ }^{54,57,58,66,67,69,72,75,78,79,87}$ As all of these studies are retrospective, the selection bias may have had an effect on the outcome. This problem is highlighted in the study of Hirano and Mori. ${ }^{48}$ These authors found significant differences between young and old patients regarding the choice of the modalities of curative treatment, due to significantly more common concomitant comorbidities in elderly. In the study of Derks et $\mathrm{al}^{53}$ the proportion of patients aged 45-60, 70-79, and $\geq 80$ year that received standard treatment was $89 \%, 75 \%$, and $35 \%$, respectively; whereas no treatment was given to $4 \%, 13 \%$, and $18 \%$ of the patients from respective groups.

Comparing survival between cohorts of different age categories is difficult due to expected differences in life expectancy. Some studies confirm poorer survival in the elderly after multimodality treatment, ${ }^{50,51,62,69,93,94}$ others report comparable survival in the elderly to the younger cohorts. ${ }^{46,47,66,75,87}$ Concerning the rate of treatmentrelated death, Sarini et $\mathrm{al}^{49}$ did not find any age-specific differences.

In the past, elderly patients were clearly underrepresented in non-age-related clinical trials. However, the number of studies on the eligibility of elderly for intensive multimodal treatment is exponentially increasing. It seems that the old dogma, that elderly patients should be excluded from standard treatment protocols, purely based on their chronological age does not stand any longer. This is also reflected in the outcome of a recent study on the SEER database, confirming the increased use of chemoradiation and particularly cetuximab, in older patients over the past decades. ${ }^{81}$

\section{3 | FACTORS INFLUENCING ADVERSE EVENTS}

\section{1 | Comorbidity, advanced stage, use of CT}

One of the key factors in the decision on treatment of a patient with HNSCC is comorbidity. Comorbidity is defined as one or more unrelated diseases present at the time of cancer diagnosis. ${ }^{10}$ In elderly patients, comorbidity is more frequent, and these patients sometimes receive nonstandard treatments due to the fear of complications, that intensive standard treatments entail. For this reason, these patients are often offered nonsurgical treatments or surgical treatment without postoperative RT. ${ }^{49,53,107}$ Peters et al ${ }^{63}$ reported on a cohort of elderly patients with oropharyngeal cancer, and no difference in posttreatment complications between young 


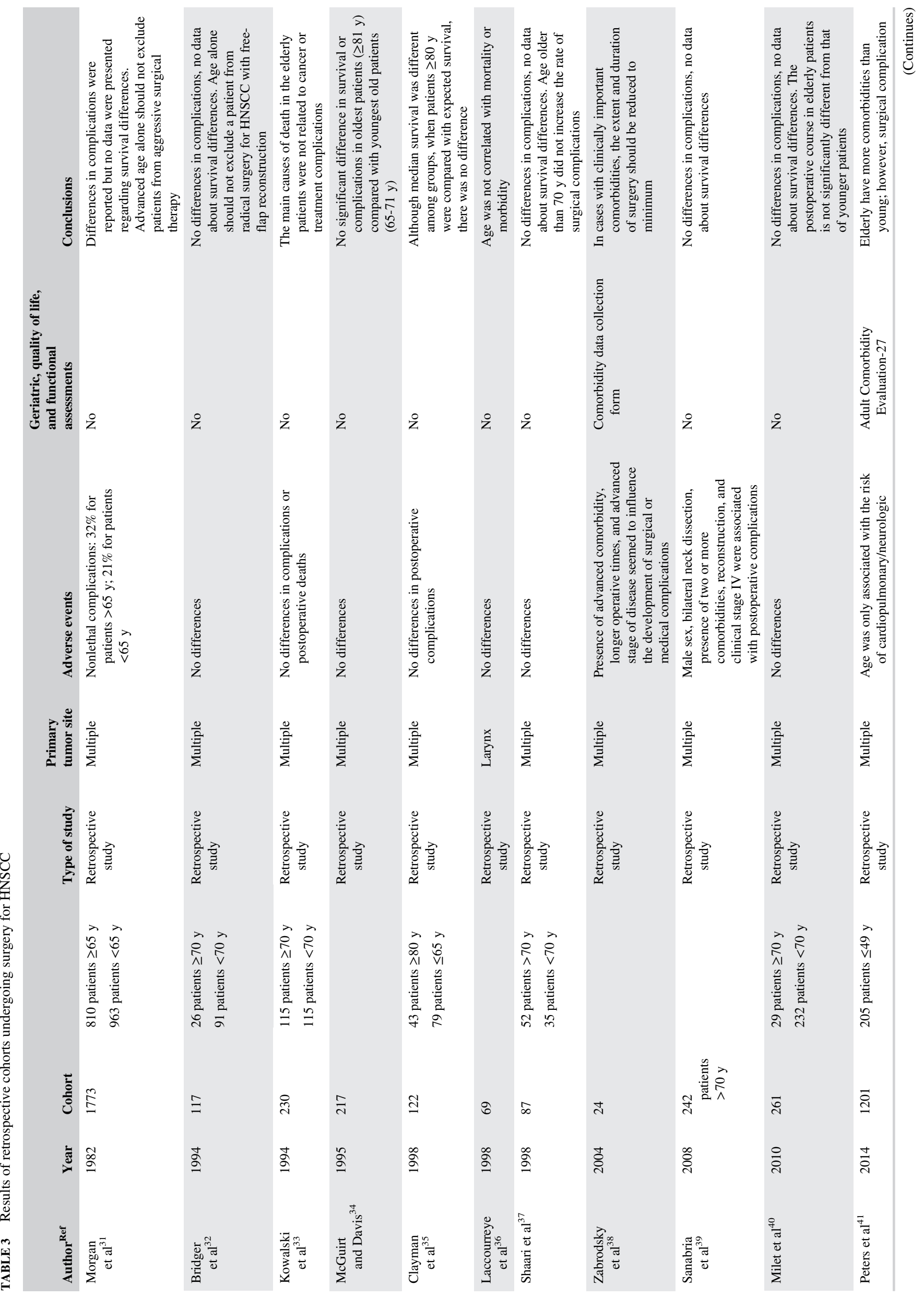




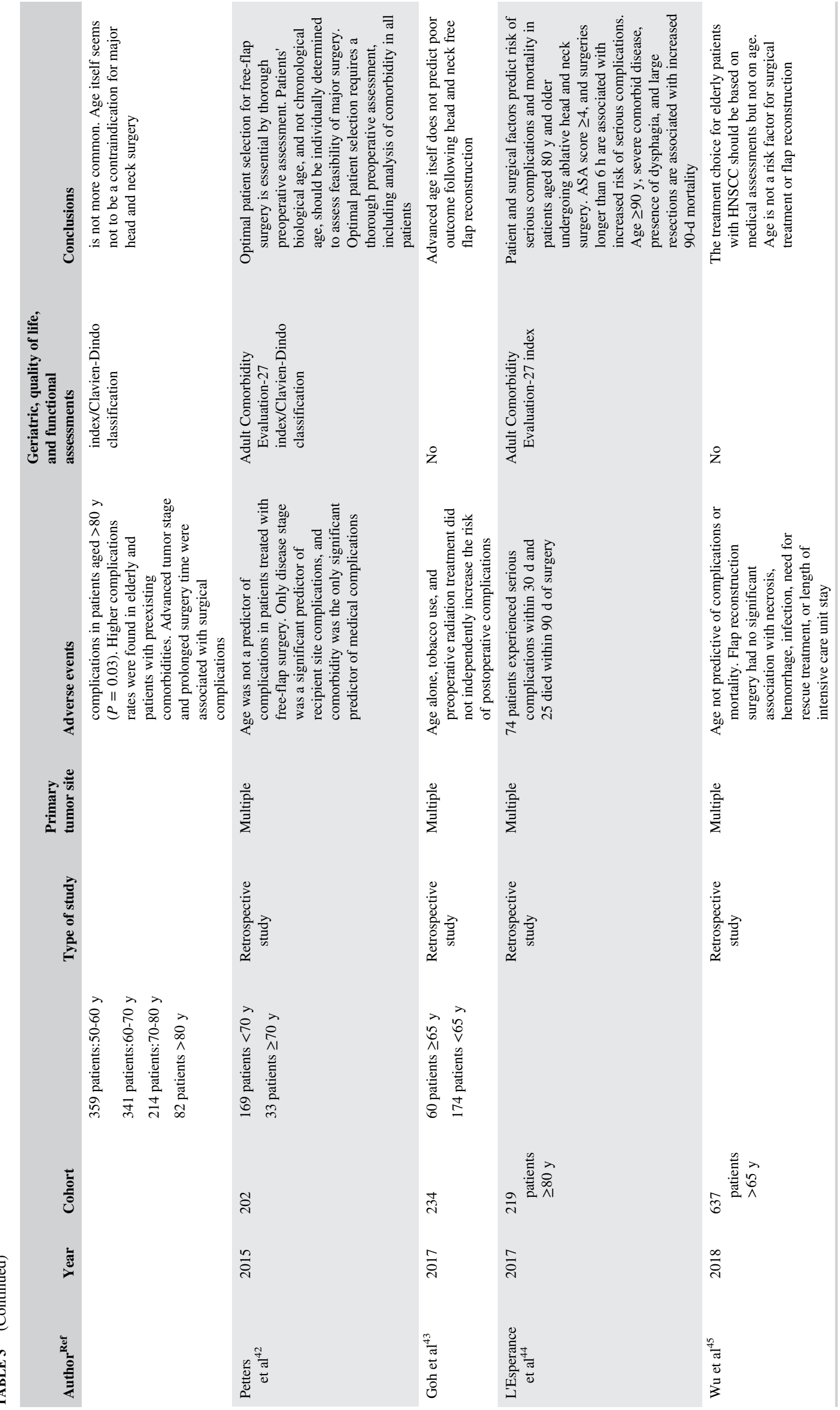




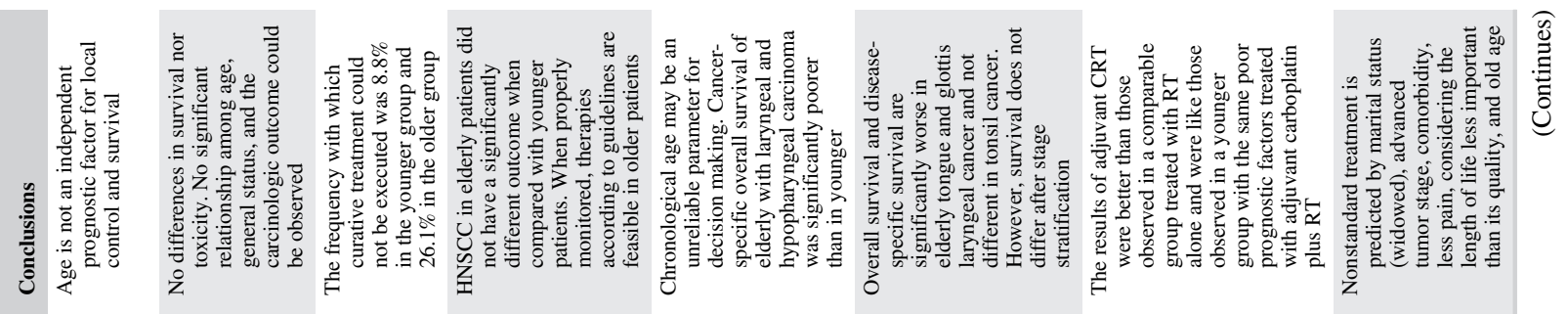

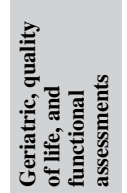

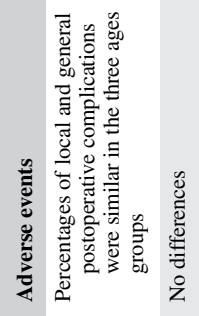

!n

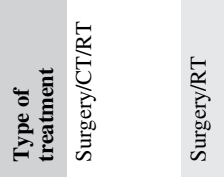
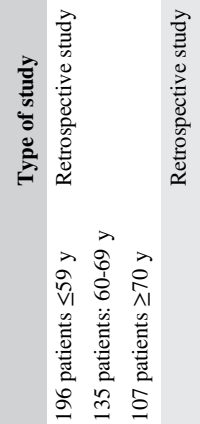

U

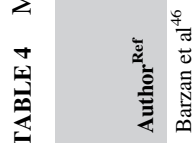

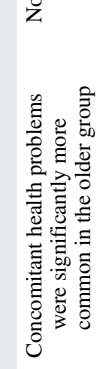

产 产<smiles>C[13CH][13CH]</smiles>

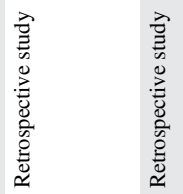

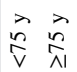

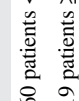

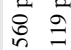

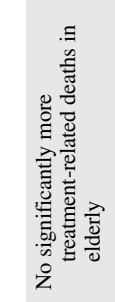

$\overleftarrow{s}$

产

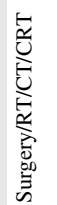

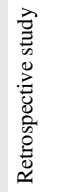

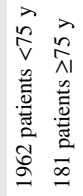

$\frac{8}{4}$

हूँ

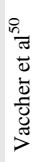

$\overleftarrow{z}$

产

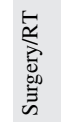

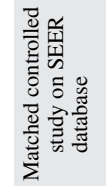

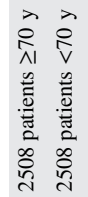

ํํำ

ఫั่

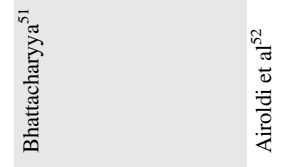

ชั
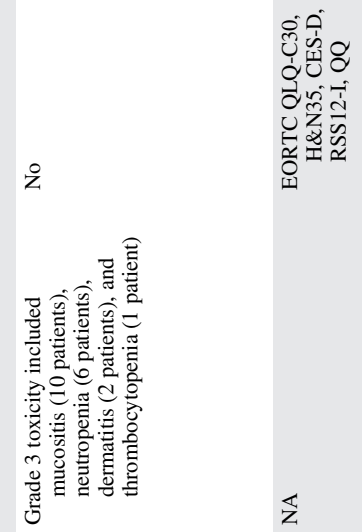

$\frac{0}{\frac{0}{E}}$

$\frac{2}{20}$

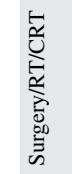

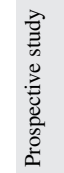

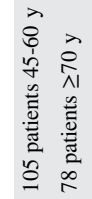

$\stackrel{\infty}{9}$

๕ั

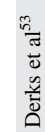




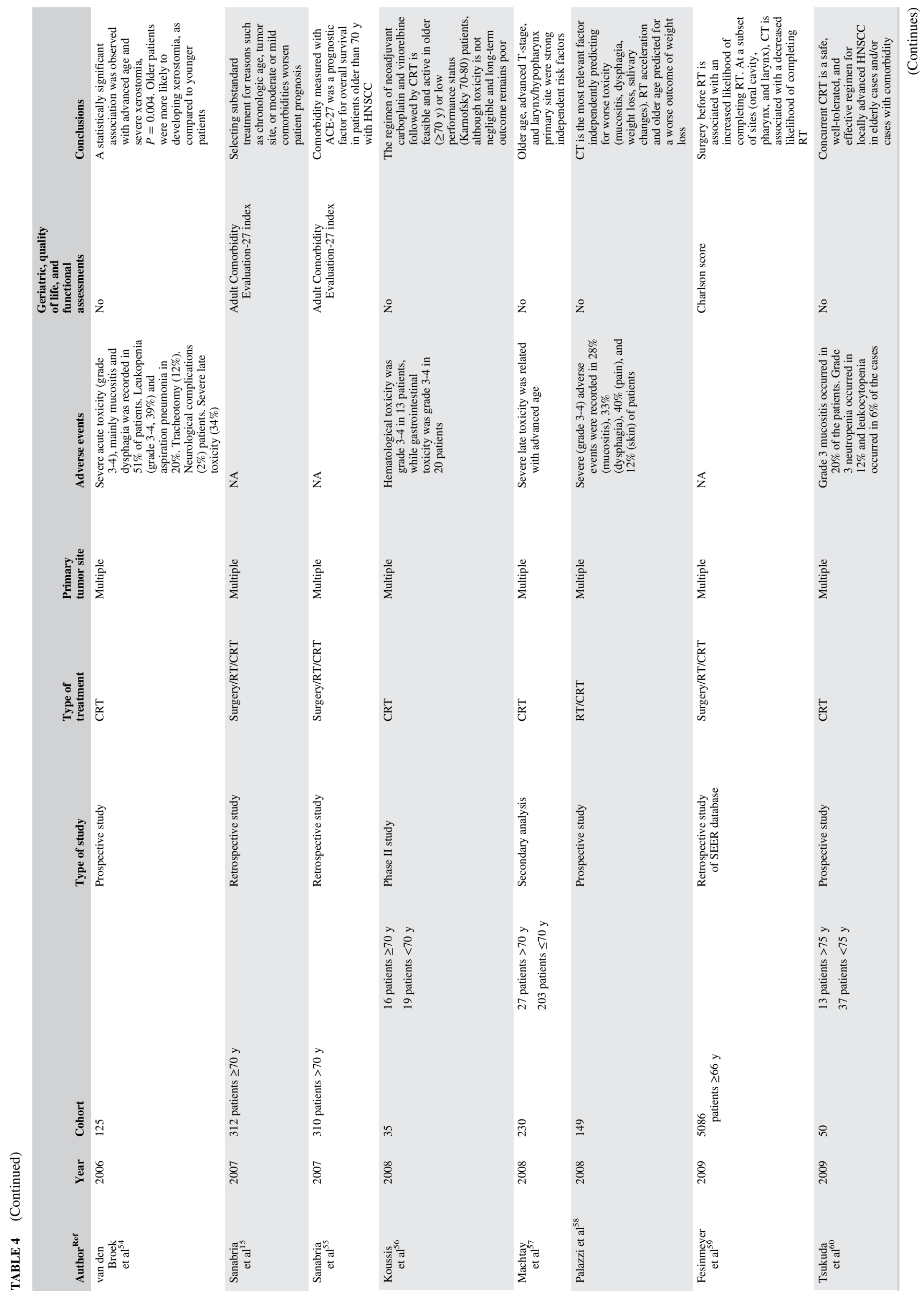



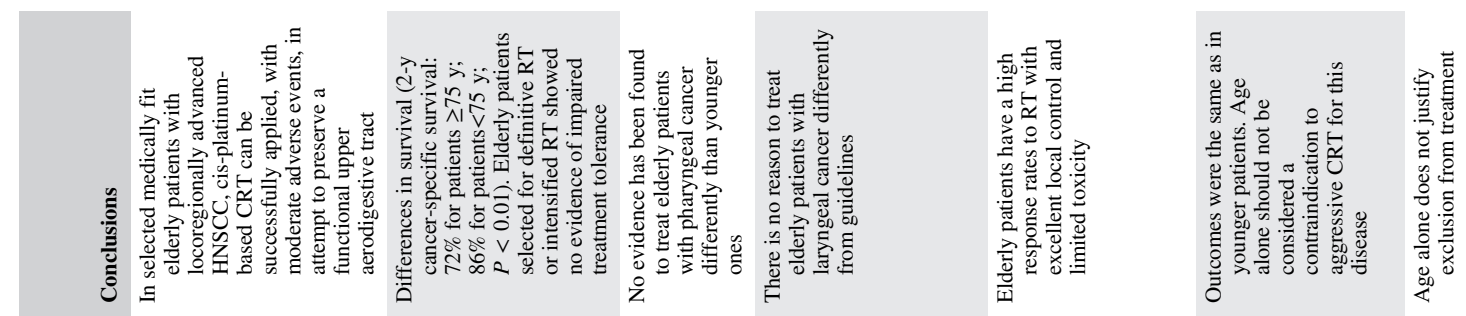

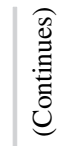

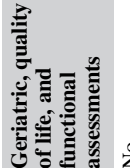

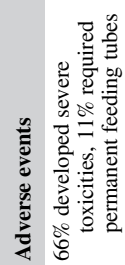

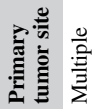

先

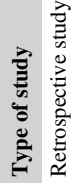

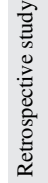

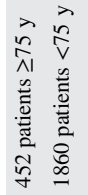

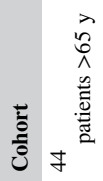

ठِ

章
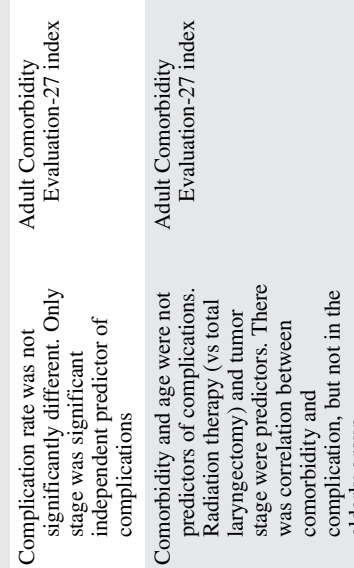

善兽

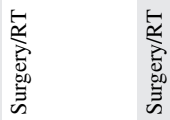

苋

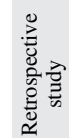

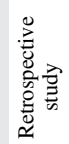

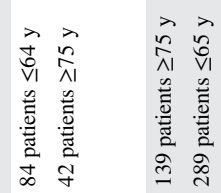

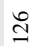

$\stackrel{\infty}{\Im}$

高

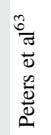

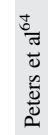

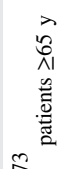

จั่

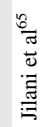

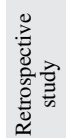

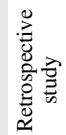

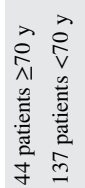

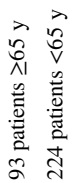

总

递

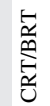

흔

ลั่

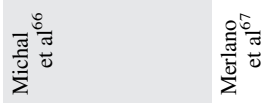



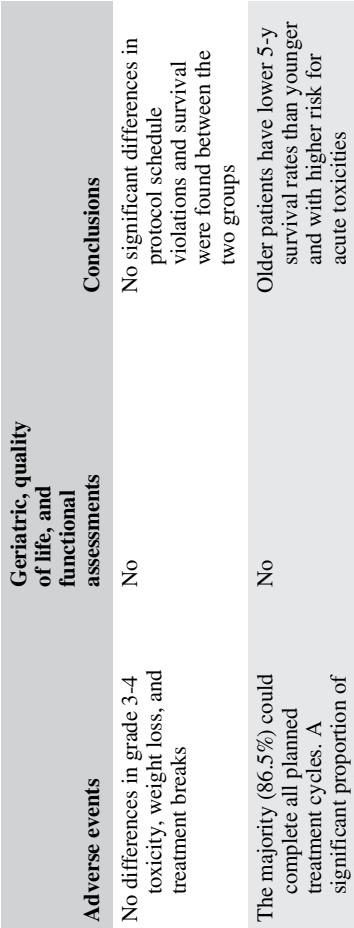

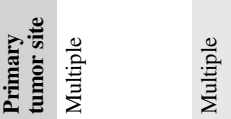

言
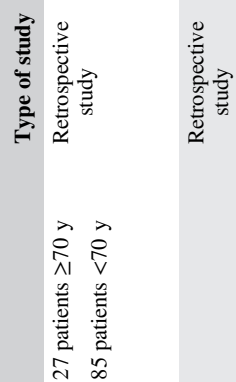

ป

己ृ

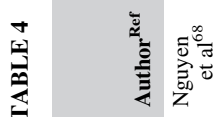

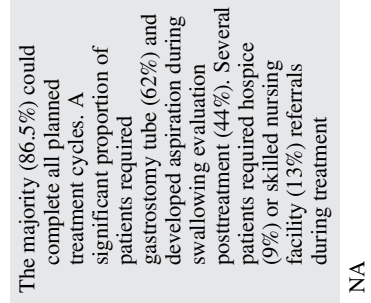

$\bar{z}$

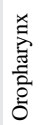

紊

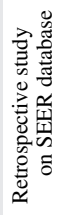

容昌高

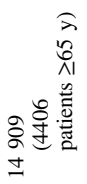

$\stackrel{4}{9}$

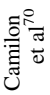

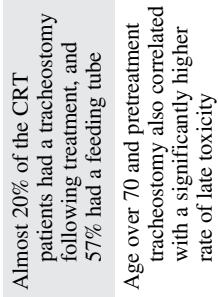

$\frac{1}{z} \quad \frac{1}{z}$

鄫产

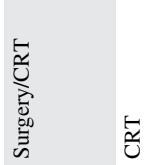

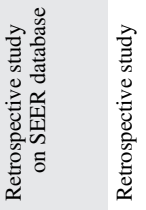

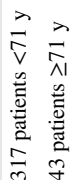

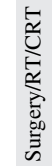

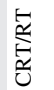
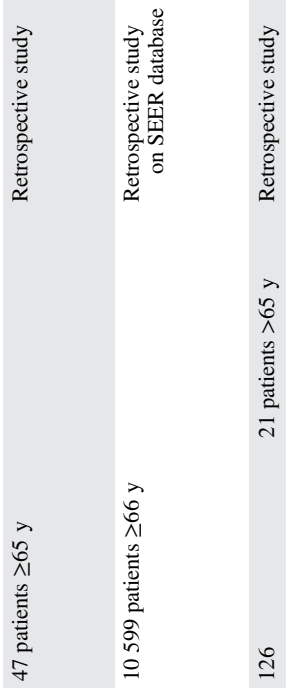

产

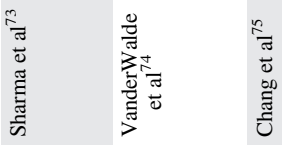

喜喜

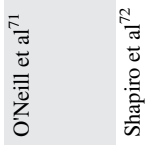

ํํำ

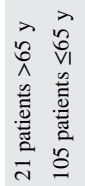

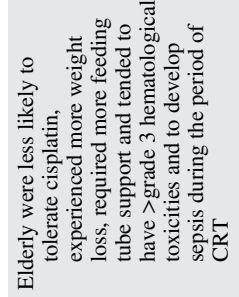

$\frac{2}{\bar{E}}$

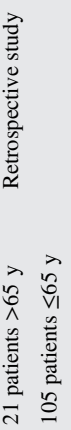

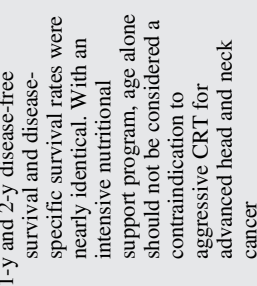

気 


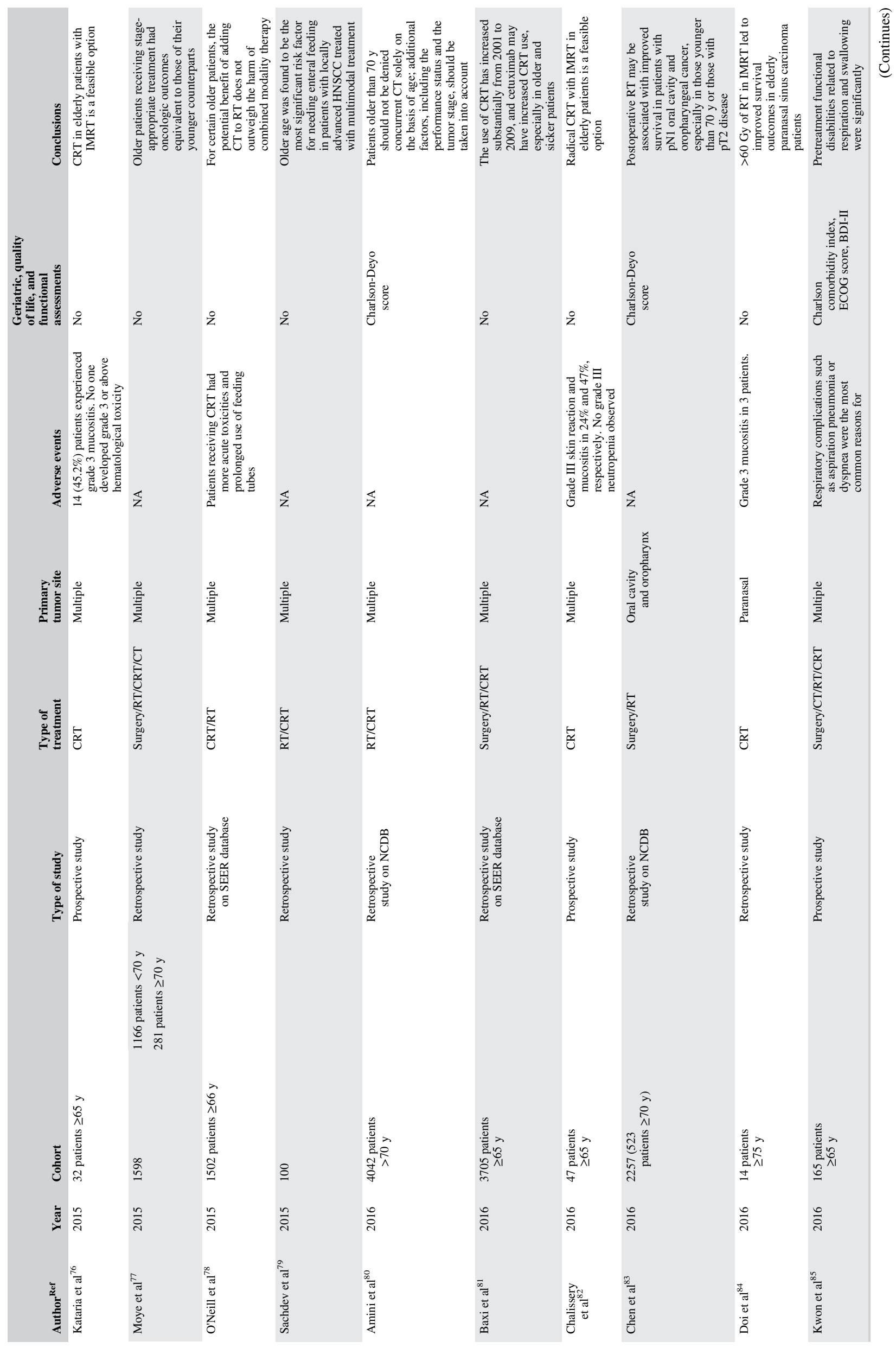




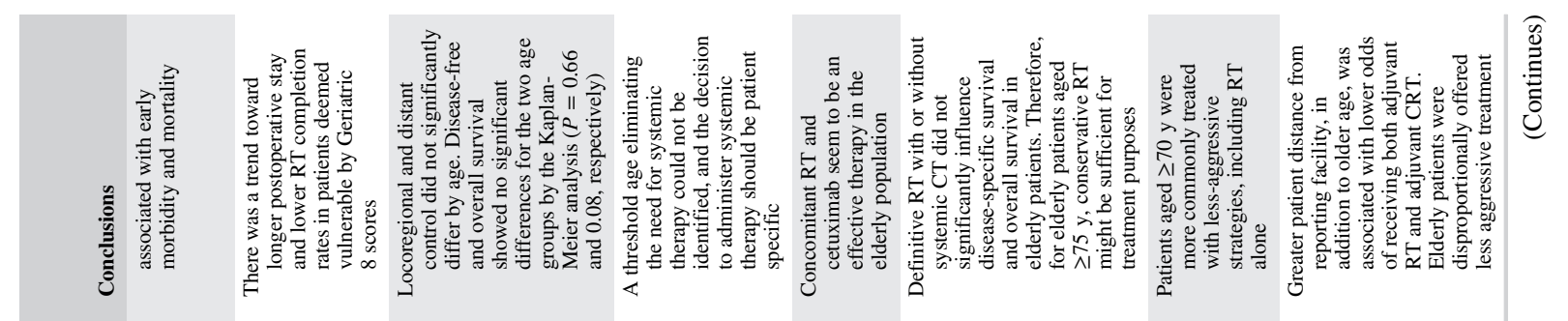

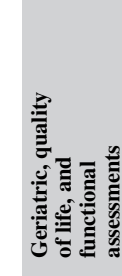

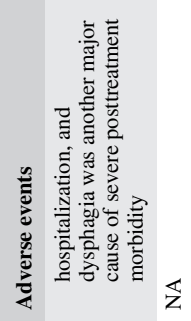

䓪

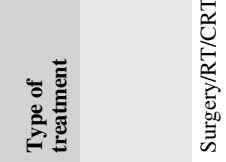
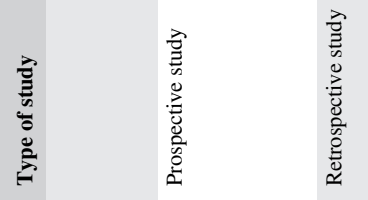

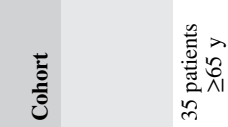

氖

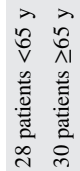
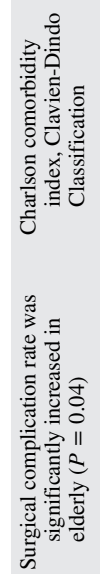

产

ڤ్

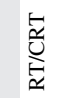

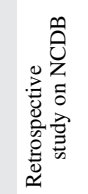

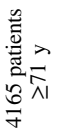

ํํำ

$\frac{\sqrt{3}}{3}$
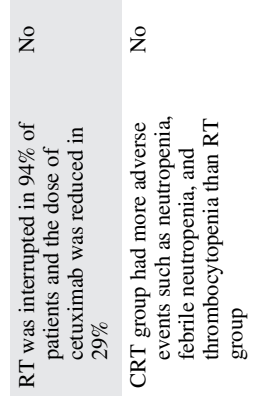

蓄 黄

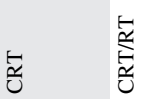

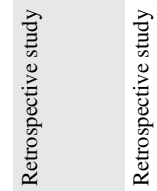

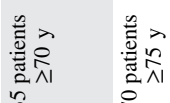

ลิ กิ

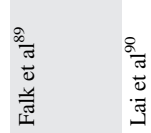
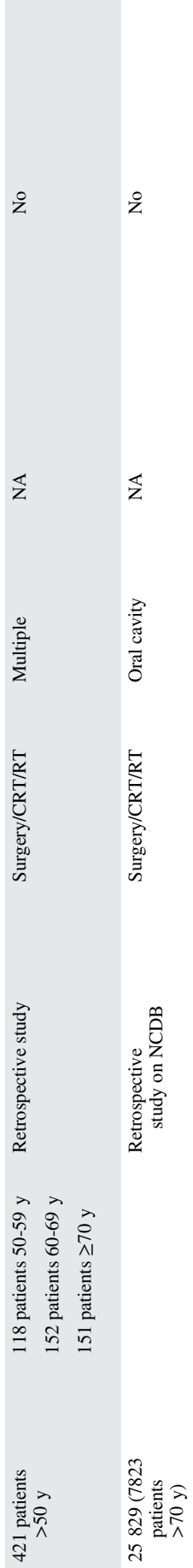

ลิ

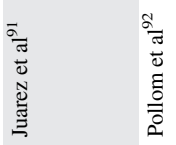




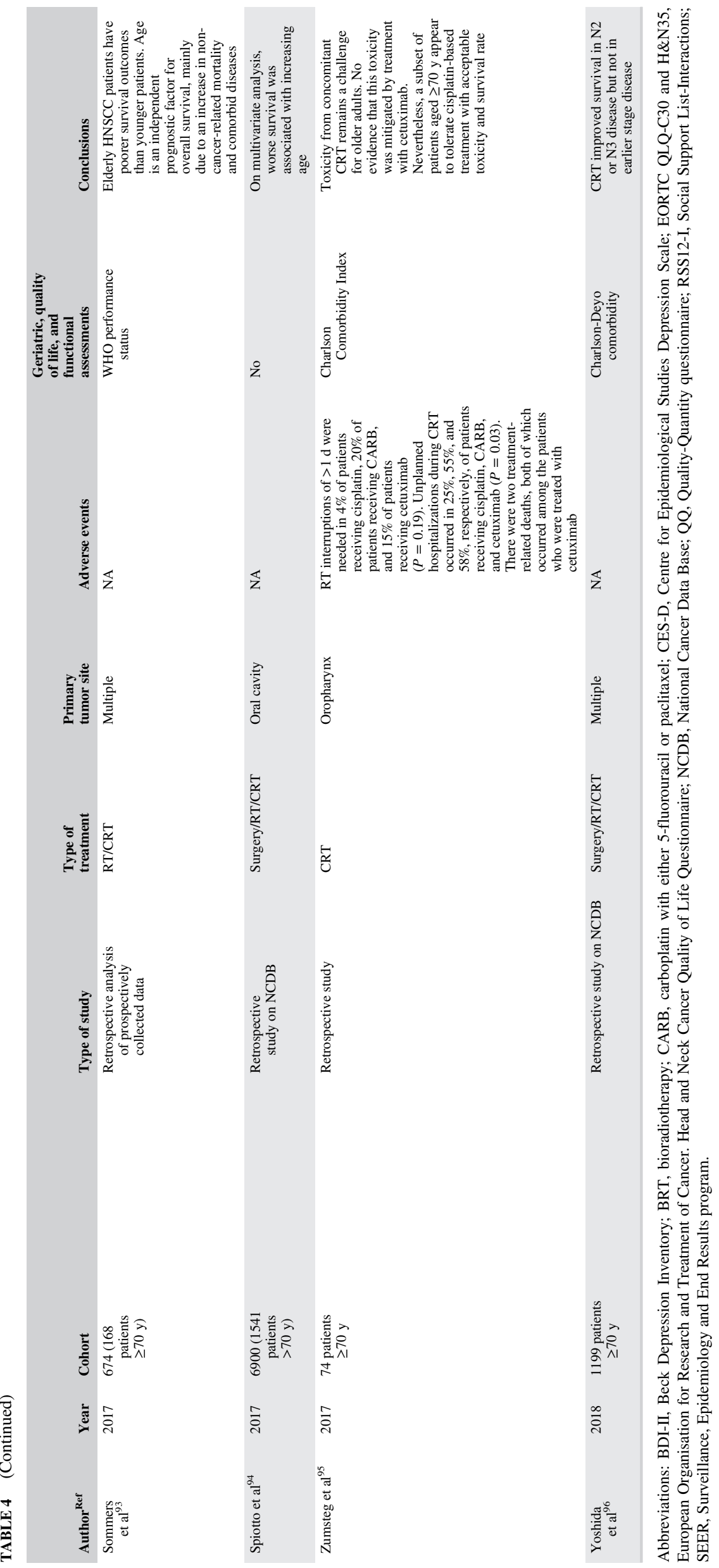


and old patients was found, despite the higher incidence of comorbidity in elderly patients. T-classification was the only factor associated with the frequency of complications in multivariate analysis. This observation was confirmed by Zabrodsky et al. ${ }^{38}$ They reported that surgical and medical complications were influenced by advanced comorbidity, long operative times, and advanced stage at diagnosis. Sanabria et $\mathrm{al}^{39}$ observed that advanced stage was associated with postoperative complications as well, and identified additional factors that contributed: male, bilateral neck dissection, and presence of two or more comorbidities. Advanced stage at diagnosis is often considered a predictor for postoperative complications. ${ }^{41,42,63,64}$ One of the factors studied as influential in the incidence of adverse effects in the elderly is the addition of CT to RT. For example, in the study by $\mathrm{O}^{\prime} \mathrm{Neill}$ et al,${ }^{78}$ a higher rate of hospitalization and acute toxicity with emergency room visit was found in patients receiving CRT vs RT treatment. The group also reported a higher rate of acute treatment-related toxicity, feeding tube placement, and long-term feeding tube dependence among these older patients treated with combined modality therapy. Similar results were reported by Strom et al. ${ }^{108}$ This report evaluated patients by age, rather than by treatment modality, and found an increased rate of hospital admission and a late percutaneous endoscopic gastrostomy dependence among older patients treated with CRT. Michal et $\mathrm{al}^{66}$ confirmed these observations as well.

\subsection{Other prognosticators}

Other factors possibly related to adverse events during treatment of the elderly patients with HNSCC have also been studied. Besides comparing young and elderly patients, a significant proportion of these studies attempted to identify predictors of outcome other than age. Comorbidity, performance status, frailty, and advanced tumor stage all seem to correlate with clinical outcome. ${ }^{39,56,59,63,64,67,80,83,85-87,93,95,96,106}$ Beside the known general prognosticators for surgical complications, like advanced stage and previous RT, the duration of the surgery plays a role. In fact, prolonged surgery time was found to be a significant independent predictor for surgical complication in these studies. ${ }^{38,41,44,105}$ However, the ability of older patients to cope with the proposed treatment goes beyond the comorbidity status and includes other aspect of patient functioning with assessment of the nutritional status, polypharmacy, cognitive function, socioeconomic issues, and geriatric syndromes. ${ }^{109}$

\section{3 | Coordination of care}

Apart from these observations, the majority of the authors agree that older patients can receive the same treatment as younger ones, with comparable or higher complication rates. A higher chance on complications as such does not imply not to give treatment, but calls for better planning, better preoperative evaluation, and optimal multidisciplinary team coordination, including supportive care, to minimize treatment-related complications, maximize postoperative or post-(chemo)radiotherapy support and decrease the impact on survival and QoL. Introduction of enhanced recovery after surgery (ERAS) strategy in other oncologic procedures can be considered a demonstration of this philosophy. The ERAS programs have been applied successfully in the last two decades to offer a faster recovery, reducing hospital stay, and thus fostering early return to daily activities after hospital discharge. ${ }^{110}$

Other factors that are important for optimal recovery and QoL after treatment are social and family support, caregivers' availability and resilience, and financial support. Studies have demonstrated that living alone, ${ }^{111}$ lack of psychological support, ${ }^{112}$ and lack of social support ${ }^{113}$ are prognostic factors of QOL decline after treatment.

\section{I THE SELECTION OF PATIENTS FOR THERAPY}

\section{1 | Comprehensive geriatric assessment (CGA) and frailty tests}

Attempting to predict adverse events of a given treatment in elderly patients is much more difficult than in young patients. It is preferable in elderly patients to evaluate the potential impacts of treatment on the QoL, survival, and the potential for adverse events. With this knowledge, older patients who may benefit from intensified treatment can be better selected for the most appropriate treatment. One of the available options for this assessment is the CGA which is defined as a "multidimensional interdisciplinary diagnostic process focused on determining a frail older person's medical, psychological and functional capability in order to develop a coordinated and integrated plan for treatment and long term follow up." 114 CGA is therefore both a diagnostic and therapeutic tool. It seeks to ensure that problems are identified, quantified, and managed appropriately. A CGA is now considered as the gold standard by some authors to assess whether individual patients can undergo a certain (radical) treatment, or not, based on their vulnerability. However, as suggested by Neve et al, ${ }^{86}$ to avoid overuse of this complex time-consuming assessment instrument, the most feasible option is to use a "screening" tool first, in order to identify patients who are truly "vulnerable" and therefore require further examination by a CGA (two-step approach). Other patients recognized in the screening phase as "fit" do not require further examination. In order to identify frail patients, several tools are available, like the Geriatric 8 (G8), the Flemish version of the Triage Risk Screening Tool (fTRST), the Groningen Frailty Indicator (GFI), the Vulnerable Elders Survey-13 (VES-13), and an abbreviated CGA. ${ }^{115}$ 


\subsection{Predictive value of CGA items and frailty tests}

As described by Hamaker et $\mathrm{al}^{11}$ in a recent systematic review, the predictive value of these frailty tests can be questioned as some tests are highly sensitive for frailty but their specificity and negative predictive value are rather poor. In HNSCC, the G8 appears to be the diagnostic screening tool with a greater ability to select vulnerable patients, who should need a full CGA. ${ }^{116}$ In our review, only 2 studies use some kind of geriatric, QoL, or functional assessments among the RT trials, ${ }^{24,25}$ 2 studies of the trial on systemic therapy, ${ }^{26,29} 4$ in surgical studies, ${ }^{38,41,42,44}$ and 17 in papers on results of multimodal treatment. ${ }^{15,53,55,59,63,64,67,80,83,85-87,93,95,96,106,117}$ Most of them did not use a specific geriatric tool. As it is known that the selection of a substandard treatment for an elderly patient decreases overall and cancer-specific survival, this decision must be based on the results of the available screening tools and eventual CGA, not simply on chronological age.

\section{I CONCLUSIONS AND RECOMMENDATIONS}

This is the first comprehensive review which systematically assesses age-related adverse events and treatment selection in elderly patients with HNSCC and associated survival outcomes. Most of the studies agree that chronological age itself should not to be a reason to exclude patients from standard therapy. However, these data are mostly based on retrospective studies, which might introduce selection bias. Furthermore, the quality of the studies is diverse, and some data are controversial. When selecting treatment modalities, biological age is clearly more important than chronological age. However, there is no gold standard to assess it. Comorbidity and performance status of the patients are frequently analyzed and are certainly important factors, but as such seem to be insufficient to predict treatment outcome. In fact, tolerance to treatment is multifactorial and also depends on psychological status and various socioeconomic issues, in addition to medical condition and the level of functioning. Pretreatment assessment remains a crucial issue in treatment selection. However, choosing the proper therapy remains challenging. This process is even more complex, as patients' preferences also need to be considered in the context of the shared decision making and elderly are known to have other priorities than their younger counterparts. Using frailty screening instruments, only selected candidate patients may be directed to more complex CGA evaluation (two-step approach). Other promising screening tools need further investigation of their impact in guiding the treatment decision making and in predicting toxicities, in the framework of HNSCC prospective trials. Large scale, prospective, multicenter studies are also needed to explore the possibility of including more elderly HNSCC patients in guideline-based (intensive) treatment protocols, and to select appropriate deintensified approaches for non-fit patients.

\section{ORCID}

Andrés Coca-Pelaz (1D https://orcid.org/0000-0003-13638559

Gyorgy B. Halmos (1) https://orcid.org/0000-0003-24602260

Primož Strojan (10) https://orcid.org/0000-0002-0445-112X

Remco de Bree (1) https://orcid.org/0000-0001-7128-5814

Paolo Bossi (1D https://orcid.org/0000-0003-0135-0224

Carol R. Bradford (10) https://orcid.org/0000-0002-2768-4532

Alessandra Rinaldo (10) https://orcid.org/0000-0001-7956-

6709

Vincent Vander Poorten (10 https://orcid.org/0000-0003-

1341-829X

Alvaro Sanabria (1D https://orcid.org/0000-0002-5563-8840

Robert P. Takes (D) https://orcid.org/0000-0003-4784-0499

Alfio Ferlito (D https://orcid.org/0000-0002-8247-8002

\section{REFERENCES}

1. National Cancer Institute. Surveillance, epidemiology, and end results program. https://seer.cancer.gov/. Accessed September 21, 2017.

2. Muir CS, Fraumeni JF, Doll R. The interpretation of time trends. Cancer Surv. 1994;19-20:5-21.

3. Syrigos KN, Karachalios D, Karapanagiotou EM, Nutting CM, Manolopoulos L, Harrington KJ. Head and neck cancer in the elderly: an overview on the treatment modalities. Cancer Treat Rev. 2009;35:237-245.

4. Pignon T, Horiot JC, Van Den Bogaert W, Van Glabbeke M, Scalliet P. No age limit for radical radiotherapy in head and neck tumours. Eur J Cancer. 1996;32:2075-2081.

5. Balducci L. Management of cancer in the elderly. Oncology. 2006;20: 135-143.

6. Haddad RI, Shin DM. Recent advances in head and neck cancer. $N$ Engl J Med. 2008;359:1143-1154.

7. Fentiman IS, Tirelli U, Monfardini S, et al. Cancer in the elderly: why so badly treated? Lancet. 1990;335:1020-1022.

8. VanderWalde NA, Fleming M, Weiss J, Chera BS. Treatment of older patients with head and neck cancer: a review. Oncologist. 2013;18:568-578.

9. Bernier J. Head and Neck Cancer. Switzerland: Springer International Publishing; 2006:613.

10. Teymoortash A, Halmos GB, Silver CE, et al. On the need for comprehensive assessment of impact of comorbidity in elderly patients with head and neck cancer. Eur Arch Otorhinolaryngol. 2014;271:2597-2600.

11. Hamaker ME, Jonker JM, de Rooij SE, Vos AG, Smorenburg CH, van Munster BC. Frailty screening methods for predicting outcome of a comprehensive geriatric assessment in elderly patients with cancer: a systematic review. Lancet Oncol. 2012;13:437-444.

12. Rockwood K, Mitnitski A. Frailty defined by deficit accumulation and geriatric medicine defined by frailty. Clin Geriatr Med. 2011;27:17-26.

13. Maas HAAM, Janssen-Heijnen MLG, Olde Rikkert MGM, Machteld Wymenga AN. Comprehensive geriatric assessment and its clinical impact in oncology. Eur J Cancer. 2007;43:2161-2169.

14. Siddiqui F, Gwede CK. Head and neck cancer in the elderly population. Semin Radiat Oncol. 2012;22:321-333.

15. Sanabria A, Carvalho AL, Vartanian JG, Magrin J, Ikeda MK, Kowalski LP. Factors that influence treatment decision in older patients with resectable head and neck cancer. Laryngoscope. 2007;117:835-840.

16. Shamseer L, Moher D, Clarke M, et al. Preferred Reporting Items for Systematic Review and Meta-Analysis Protocols (PRISMA-P) 2015: elaboration and explanation. BMJ. 2015;350:g7647. 
17. Huguenin P, Sauer M, Glanzmann C, Lütolf UM. Radiotherapy for carcinomas of the head and neck in elderly patients. Strahlenther Onkol. 1996; 172:485-488.

18. Zachariah B, Balducci L, Venkattaramanabalaji G, Casey L, Greenberg HM, DelRegato JA. Radiotherapy for cancer patients aged 80 and older: a study of effectiveness and side effects. Int J Radiat Oncol Biol Phys. 1997;39:1125-1129.

19. Mitsuhashi N, Hayakawa K, Yamakawa M, et al. Cancer in patients aged 90 years or older: radiation therapy. Radiology. 1999;211:829-833.

20. Allal AS, Maire D, Becker M, Dulguerov P. Feasibility and early results of accelerated radiotherapy for head and neck carcinoma in the elderly. Cancer. 2000;88:648-652.

21. Schofield CP, Sykes AJ, Slevin NJ, Rashid NZZ. Radiotherapy for head and neck cancer in elderly patients. Radiother Oncol. 2003;69:37-42.

22. Yu JB, Soulos PR, Sharma R, et al. Patterns of care and outcomes associated with intensity-modulated radiation therapy versus conventional radiation therapy for older patients with head-and-neck cancer. Int $J$ Radiat Oncol Biol Phys. 2012;83:e101-e107.

23. Straube C, Pigorsch SU, Scherb H, Wilkens JJ, Bier H, Combs SE. Reduced volume SIB-IMRT/IGRT to head and neck cancer in elderly and frail patients: outcome and toxicity. Radiat Oncol. 2016;11:133.

24. Bonomo P, Desideri I, Loi M, et al. Elderly patients affected by head and neck squamous cell carcinoma unfit for standard curative treatment: is deintensified, hypofractionated radiotherapy a feasible strategy? Oral Oncol. 2017;74:142-147.

25. De Felice F, Galdieri A, Abate G, Bulzonetti N, Musio D, Tombolini V. Definitive intensity-modulated radiation therapy in elderly patients with locally advanced oropharyngeal cancer. In Vivo. 2017;31:455-459.

26. Gebbia V, Di Marco P, Citarrella P. Systemic chemotherapy in elderly patients with locally advanced and/or inoperable squamous cell carcinoma of the head and neck: impact of anemia and role of recombinant human erythropoietin. Crit Rev Oncol Hematol. 2003;48:49-55.

27. Argiris A, Li Y, Murphy BA, Langer CJ, Forastiere AA. Outcome of elderly patients with recurrent or metastatic head and neck cancer treated with cisplatin-based chemotherapy. J Clin Oncol. 2004;22:262-268.

28. Vermorken JB, Mesia R, Rivera F, et al. Platinum-based chemotherapy plus cetuximab in head and neck cancer. $N$ Engl J Med. 2008;359:11161127.

29. Clement PM, Gauler T, Machiels JP, et al. Afatinib versus methotrexate in older patients with second-line recurrent and/or metastatic head and neck squamous cell carcinoma: subgroup analysis of the LUX-Head \& Neck 1 trial. Ann Oncol. 2016;27:1585-1593.

30. Nakano K, Marshall S, Taira S, et al. A comparison of weekly paclitaxel and cetuximab with the EXTREME regimen in the treatment of recurrent/metastatic squamous cell head and neck carcinoma. Oral Oncol. 2017;73: 21-26.

31. Morgan RF, Hirata RM, Jaques DA, Hoopes JE. Head and neck surgery in the aged. Am J Surg. 1982;144:449-451.

32. Bridger AG, O'Brien CJ, Lee KK. Advanced patient age should not preclude the use of free-flap reconstruction for head and neck cancer. Am J Surg. 1994;168:425-428.

33. Kowalski LP, Alcantara PS, Magrin J, Parise Junior O. A case-control study on complications and survival in elderly patients undergoing major head and neck surgery. Am J Surg. 1994;168:485-490.

34. McGuirt WF, Davis SP 3rd. Demographic portrayal and outcome analysis of head and neck cancer surgery in the elderly. Arch Otolaryngol Head Neck Surg. 1995;121:150-154.

35. Clayman GL, Eicher SA, Sicard MW, Razmpa E, Goepfert H. Surgical outcomes in head and neck cancer patients 80 years of age and older. Head Neck. 1998;20:216-223.

36. Laccourreye O, Brasnu D, Périé S, Muscatello L, Ménard M, Weinstein G. Supracricoid partial laryngectomies in the elderly: mortality, complications, and functional outcome. Laryngoscope. 1998;108:237-242.

37. Shaari CM, Buchbinder D, Costantino PD, Lawson W, Biller HF, Urken ML. Complications of microvascular head and neck surgery in the elderly. Arch Otolaryngol Head Neck Surg. 1998;124:407-411.

38. Zabrodsky M, Calabrese L, Tosoni A, et al. Major surgery in elderly head and neck cancer patients: immediate and long-term surgical results and complication rates. Surg Oncol. 2004;13:249-255.
39. Sanabria A, Carvalho AL, Melo RL, et al. Predictive factors for complications in elderly patients who underwent head and neck oncologic surgery. Head Neck. 2008;30:170-177.

40. Milet PR, Mallet Y, El Bedoui S, Penel N, Servent V, Lefebvre JL. Head and neck cancer surgery in the elderly—does age influence the postoperative course? Oral Oncol. 2010;46:92-95.

41. Peters TT, van Dijk BA, Roodenburg JL, van der Laan BF, Halmos GB. Relation between age, comorbidity, and complications in patients undergoing major surgery for head and neck cancer. Ann Surg Oncol. 2014;21: 963-970.

42. Peters TT, Post SF, van Dijk BA, et al. Free flap reconstruction for head and neck cancer can be safely performed in both young and elderly patients after careful patient selection. Eur Arch Otorhinolaryngol. 2015;272:29993005.

43. Goh CSL, Kok YO, Yong CP, et al. Outcome predictors in elderly head and neck free flap reconstruction: a retrospective study and systematic review of the current evidence. J Plast Reconstr Aesthetic Surg. 2018;71 (5):719-728.

44. L'Esperance HE, Kallogjeri D, Yousaf S, Piccirillo JF, Rich JT. Prediction of mortality and morbidity in head and neck cancer patients 80 years of age and older undergoing surgery. Laryngoscope. 2018;128:871-877.

45. Wu Y, Zhang B, Huang Z, Ruan Y, Huang Z. Study of surgical treatment for elderly patients with head and neck cancer. Int J Oral Maxillofac Surg. 2018;47:824-829.

46. Barzan L, Veronesi A, Caruso G, et al. Head and neck cancer and ageing: a retrospective study in 438 patients. J Laryngol Otol. 1990;104:634-640.

47. Lusinchi A, Bourhis J, Wibault P, Le Ridant AM, Eschwege F. Radiation therapy for head and neck cancers in the elderly. Int J Radiat Oncol Biol Phys. 1990;18:819-823.

48. Hirano M, Mori K. Management of cancer in the elderly: therapeutic dilemmas. Otolaryngol Head Neck Surg. 1998;118:110-114.

49. Sarini J, Fournier C, Lefebvre JL, Bonafos G, Van JT, Coche-Dequeant B. Head and neck squamous cell carcinoma in elderly patients: a long-term retrospective review of 273 cases. Arch Otolaryngol Head Neck Surg. 2001;127:1089-1092.

50. Vaccher E, Talamini R, Franchin G, Tirelli UBL. Elderly head and neck (H-N) cancer patients: a monoinstitutional series. Tumori. 2002;88:63-66.

51. Bhattacharyya $\mathrm{N}$. A matched survival analysis for squamous cell carcinoma of the head and neck in the elderly. Laryngoscope. 2003;113:368-372.

52. Airoldi M, Cortesina G, Giordano C, et al. Postoperative adjuvant chemoradiotherapy in older patients with head and neck cancer. Arch Otolaryngol Head Neck Surg. 2004;130:161-166.

53. Derks W, de Leeuw JR, Hordijk GJ, Winnubst JA. Reasons for nonstandard treatment in elderly patients with advanced head and neck cancer. Eur Arch Otorhinolaryngol. 2005;262:21-26.

54. van den Broek GB, Balm AJM, van den Brekel MWM, Hauptmann M, Schornagel JH, Rasch CRN. Relationship between clinical factors and the incidence of toxicity after intra-arterial chemoradiation for head and neck cancer. Radiother Oncol. 2006;81:143-150.

55. Sanabria A, Carvalho AL, Vartanian JG, Magrin J, Ikeda MK, Kowalski LP. Comorbidity is a prognostic factor in elderly patients with head and neck cancer. Ann Surg Oncol. 2007;14:1449-1457.

56. Koussis H, Scola A, Bergamo F, et al. Neoadjuvant carboplatin and vinorelbine followed by chemoradiotherapy in locally advanced head and neck or oesophageal squamous cell carcinoma: a phase II study in elderly patients or patients with poor performance status. Anticancer Res. 2008;28: 1383-1388.

57. Machtay M, Moughan J, Trotti A, et al. Factors associated with severe late toxicity after concurrent chemoradiation for locally advanced head and neck cancer: an RTOG analysis. J Clin Oncol. 2008;26:3582-3589.

58. Palazzi M, Tomatis S, Orlandi E, et al. Effects of treatment intensification on acute local toxicity during radiotherapy for head and neck cancer: prospective observational study validating CTCAE, version 3.0, scoring system. Int J Radiat Oncol Biol Phys. 2008;70:330-337.

59. Fesinmeyer MD, Mehta V, Tock L, Blough D, McDermott C, Ramsey SD. Completion of radiotherapy for local and regional head and neck cancer in medicare. Arch Otolaryngol Head Neck Surg. 2009;135:860-867.

60. Tsukuda M, Ishitoya J, Mikami Y, et al. Analysis of feasibility and toxicity of concurrent chemoradiotherapy with S-1 for locally advanced squamous cell carcinoma of the head and neck in elderly cases and/or cases with comorbidity. Cancer Chemother Pharmacol. 2009;64:945-952. 
61. Boscolo-Rizzo P, Muzzi E, Trabalzini F, Gava A, Stellin M, Da Mosto MC. Functional organ preservation after chemoradiotherapy in elderly patients with loco-regionally advanced head and neck squamous cell carcinoma. Eur Arch Otorhinolaryngol. 2011;268:1349-1355.

62. Huang SH, O'Sullivan B, Waldron J, et al. Patterns of care in elderly headand-neck cancer radiation oncology patients: a single-center cohort study. Int J Radiat Oncol Biol Phys. 2011;79:46-51.

63. Peters TT, Langendijk JA, Plaat BE, et al. Co-morbidity and treatment outcomes of elderly pharyngeal cancer patients: a matched control study. Oral Oncol. 2011;47:1159-1164.

64. Peters $T$, van der Laan B, Plaat B, Wedman J, Langendijk J, Halmos G. The impact of comorbidity on treatment-related side effects in older patients with laryngeal cancer. Oral Oncol. 2011;47:56-61.

65. Jilani OK, Singh $P$, Wernicke AG, et al. Radiation therapy is well tolerated and produces excellent control rates in elderly patients with locally advanced head and neck cancers. J Geriatr Oncol. 2012;3: 337-343.

66. Michal SA, Adelstein DJ, Rybicki LA, et al. Multi-agent concurrent chemoradiotherapy for locally advanced head and neck squamous cell cancer in the elderly. Head Neck. 2012;34:1147-1152.

67. Merlano MC, Monteverde M, Colantonio I, et al. Impact of age on acute toxicity induced by bio- or chemo-radiotherapy in patients with head and neck cancer. Oral Oncol. 2012;48:1051-1057.

68. Nguyen NP, Vock J, Chi A, et al. Impact of intensity-modulated and image-guided radiotherapy on elderly patients undergoing chemoradiation for locally advanced head and neck cancer. Strahlenther Onkol. 2012;188: 677-683.

69. Maggiore RJ, Curran EK, Witt ME, Haraf DJ, Vokes EE, Cohen EEW. Survival and selected outcomes of older adults with locally advanced head/neck cancer treated with chemoradiation therapy. J Geriatr Oncol. 2013;4:327-333.

70. Camilon PR, Stokes WA, Nguyen SA, Lentsch EJ. Are the elderly with oropharyngeal carcinoma undertreated? Laryngoscope. 2014;124:20572063.

71. O'Neill CB, O'Neill JP, Atoria CL, et al. Treatment complications and survival in advanced laryngeal cancer: a population-based analysis. Laryngoscope. 2014;124:2707-2713.

72. Shapiro LQ, Sherman EJ, Riaz N, et al. Efficacy of concurrent cetuximab vs. 5-fluorouracil/carboplatin or high-dose cisplatin with intensitymodulated radiation therapy (IMRT) for locally-advanced head and neck cancer (LAHNSCC). Oral Oncol. 2014;50:947-955.

73. Sharma A, Madan R, Kumar R, et al. Compliance to therapy-elderly head and neck carcinoma patients. Can Geriatr J. 2014;17:83-87.

74. VanderWalde NA, Meyer AM, Deal AM, et al. Effectiveness of chemoradiation for head and neck cancer in an older patient population. Int J Radiat Oncol Biol Phys. 2014;89:30-37.

75. Chang PH, Yeh KY, Huang JS, Chen EY, Yang SWWC. Chemoradiotherapy in elderly patients with advanced head and neck cancer under intensive nutritional support. Asia Pac J Clin Oncol. 2015;11:228-235.

76. Kataria T, Gupta D, Bisht SS, et al. Chemoradiation in elderly patients with head and neck cancers: a single institution experience. Am J Otolaryngol. 2015;36:117-121.

77. Moye VA, Chandramouleeswaran S, Zhao N, et al. Elderly patients with squamous cell carcinoma of the head and neck and the benefit of multimodality therapy. Oncologist. 2015;20:159-165.

78. O'Neill CB, Baxi SS, Atoria CL, et al. Treatment-related toxicities in older adults with head and neck cancer: a population-based analysis. Cancer. 2015;121:2083-2089.

79. Sachdev S, Refaat T, Bacchus ID, Sathiaseelan V, Mittal BB. Age most significant predictor of requiring enteral feeding in head-and-neck cancer patients. Radiat Oncol. 2015;10:93.

80. Amini A, Jones BL, McDermott JD, et al. Survival outcomes with concurrent chemoradiation for elderly patients with locally advanced head and neck cancer according to the National Cancer Data Base. Cancer. 2016; 122:1533-1543.

81. Baxi SS, O'Neill C, Sherman EJ, et al. Trends in chemoradiation use in elderly patients with head and neck cancer: changing treatment patterns with cetuximab. Head Neck. 2016;38:165-171.

82. Chalissery JR, Sudheeran PC, Varghese KM, Venkatesan K. Radical chemo-irradiation using intensity-modulated radiotherapy for locally advanced head and neck cancer in elderly patients: experience from a tertiary care center in South India. Indian J Cancer. 2016;53:483-486.

83. Chen MM, Harris JP, Hara W, Sirjani D, Divi V. Association of postoperative radiotherapy with survival in patients with N1 oral cavity and oropharyngeal squamous cell carcinoma. JAMA Otolaryngol Head Neck Surg. 2016;142:1224-1230.

84. Doi H, Kitajima K, Tanooka M, et al. Radiotherapy in late elderly (aged 75 or older) patients with paranasal sinus carcinoma: a single institution experience. Eur Arch Otorhinolaryngol. 2016;273:4485-4492.

85. Kwon M, Kim S-A, Roh J-L, et al. An introduction to a head and neck cancer-specific frailty index and its clinical implications in elderly patients: a prospective observational study focusing on respiratory and swallowing functions. Oncologist. 2016;21:1091-1098.

86. Neve $M$, Jameson $M$, Govender $S$, Hartopeanu C. Impact of geriatric assessment on the management of older adults with head and neck cancer: a pilot study. J Geriatr Oncol. 2016;7:457-462.

87. Teymoortash A, Bohne F, Kissing L, et al. Oncological and surgical outcome of total laryngectomy in combination with neck dissection in the elderly. Eur Arch Otorhinolaryngol. 2016;273:1825-1833.

88. Ward MC, Reddy CA, Adelstein DJ, Koyfman SA. Use of systemic therapy with definitive radiotherapy for elderly patients with head and neck cancer: a National Cancer Data Base analysis. Cancer. 2016;122:34723483.

89. Falk AT, Hébert C, Tran A, et al. Radiotherapy for elderly patients and cetuximab, a monocentric study. Eur Arch Otorhinolaryngol. 2017;274: 1061-1065.

90. Lai K, Lin J, Lu H, Liang C, Chen M. Is definitive concurrent chemoradiotherapy effective for locally advanced head and neck cancer in the elderly aged $\geq 75$ years: a single-institute, retrospective, cohort study. AsiaPacific J Clin Oncol. 2018;14(3):247-255.

91. Juarez JE, Choi J, St John M, Abemayor E, TenNapel M, Chen AM. Patterns of care for elderly patients with locally advanced head and neck cancer. Int J Radiat Oncol Biol Phys. 2017;98:767-774.

92. Pollom EL, Chin AL, Lee NY, Tsai CJ. Patterns of care in adjuvant therapy for resected oral cavity squamous cell cancer in elderly patients. Int J Radiat Oncol Biol Phys. 2017;98:758-766.

93. Sommers LW, Steenbakkers RJHM, Bijl HP, et al. Survival patterns in elderly head and neck squamous cell carcinoma patients treated with definitive radiation therapy. Int J Radiat Oncol Biol Phys. 2017;98:793-801.

94. Spiotto MT, Jefferson G, Wenig B, Markiewicz M, Weichselbaum RR, Koshy M. Differences in survival with surgery and postoperative radiotherapy compared with definitive chemoradiotherapy for oral cavity cancer: a National Cancer Database analysis. JAMA Otolaryngol Head Neck Surg. 2017;143:691-699.

95. Zumsteg ZS, Lok BH, Ho AS, et al. The toxicity and efficacy of concomitant chemoradiotherapy in patients aged 70 years and older with oropharyngeal carcinoma in the intensity-modulated radiotherapy era. Cancer. 2017; 123:1345-1353.

96. Yoshida EJ, Luu M, David JM, et al. Postoperative chemoradiotherapy in patients with head and neck cancer aged 70 or older with positive margins or extranodal extension and the influence of nodal classification. Head Neck. 2018;40:1228-1236.

97. Woodhouse KW, Wynne H, Baillie S, James OF, Rawlins MD. Who are the frail elderly? Q J Med. 1988;68:505-506.

98. Bourhis J, Overgaard J, Audry H, et al. Hyperfractionated or accelerated radiotherapy in head and neck cancer: a meta-analysis. Lancet. 2006;368: 843-854.

99. Lacas B, Bourhis J, Overgaard J, et al. Role of radiotherapy fractionation in head and neck cancers (MARCH): an updated meta-analysis. Lancet Oncol. 2017;18:1221-1237.

100. Bourhis $\mathrm{J}$, Le Ma1^tre A, Pignon $\mathrm{J}$, et al. Impact of age on treatment effect in locally advanced head and neck cancer (HNC): two individual patient data meta-analyses. J Clin Oncol. 2006;24:5501.

101. Khalil AA, Bentzen SM, Bernier J, et al. Compliance to the prescribed dose and overall treatment time in five randomized clinical trials of altered fractionation in radiotherapy for head-and-neck carcinomas. Int J Radiat Oncol Biol Phys. 2003;55:568-575.

102. Pignon JP, le Maître A, Maillard E, Bourhis J. Meta-analysis of chemotherapy in head and neck cancer (MACH-NC): an update on 93 randomised trials and 17,346 patients. Radiother Oncol. 2009;92:4-14. 
103. Bonner JA, Harari PM, Giralt J, et al. Radiotherapy plus cetuximab for squamous-cell carcinoma of the head and neck. $N$ Engl J Med. 2006;354: 567-578.

104. Bonner JA, Harari PM, Giralt J, et al. Radiotherapy plus cetuximab for locoregionally advanced head and neck cancer: 5-year survival data from a phase 3 randomised trial, and relation between cetuximab-induced rash and survival. Lancet Oncol. 2010;11:21-28.

105. Peters TT, van Dijk BA, Roodenburg JL, et al. Predictors of postoperative complications and survival in patients with major salivary glands malignancies: a study highlighting the influence of age. Head Neck. 2014;36:369-374.

106. Halmos GB, Peters TTA, Roodenburg JLN, Van Dijk BAC, Van Der Laan BFAM. Comorbidity, complications, and survival of sinonasal malignancies in young and elderly treated by surgery. Otolaryngol Head Neck Surg. 2013;148:860-866.

107. Halmos GB, Bras L, Siesling S, van der Laan BFAM, Langendijk JA, van Dijk BAC. Age-specific incidence and treatment patterns of head and neck cancer in the Netherlands-a cohort study. Clin Otolaryngol. 2018;43:317-324.

108. Strom TJ, Naghavi AO, Trotti AM, et al. Increased acute mortality with chemoradiotherapy for locally advanced head and neck cancer in patients $>70$ years. J Geriatr Oncol. 2017;8:50-55.

109. Gosney MA. Clinical assessment of elderly people with cancer. Lancet Oncol. 2005;6:790-797.

110. Bianchini C, Pelucchi S, Pastore A, Feo CV, Ciorba A. Enhanced recovery after surgery (ERAS) strategies: possible advantages also for head and neck surgery patients? Eur Arch Otorhinolaryngol. 2014;271:439-443.

111. Wells $M$, Cunningham $M$, Lang $H$, et al. Distress, concerns and unmet needs in survivors of head and neck cancer: a cross-sectional survey. Eur J Cancer Care. 2015;24:748-760.
112. Richardson AE, Morton R, Broadbent E. Psychological support needs of patients with head and neck cancer and their caregivers: a qualitative study. Psychol Health. 2015;30:1288-1305.

113. Penedo FJ, Traeger L, Benedict $C$, et al. Perceived social support as a predictor of disease-specific quality of life in head-and-neck cancer patients. J Support Oncol. 2012;10:119-123.

114. Rubenstein LZ, Stuck AE, Siu AL, Wieland D. Impacts of geriatric evaluation and management programs on defined outcomes: overview of the evidence. J Am Geriatr Soc. 1991;39:8-16.

115. Bellera CA, Rainfray M, Mathoulin-Pélissier S, et al. Screening older cancer patients: first evaluation of the G-8 geriatric screening tool. Ann Oncol. 2012;23:2166-2172.

116. Pottel L, Lycke M, Boterberg $T$, et al. Serial comprehensive geriatric assessment in elderly head and neck cancer patients undergoing curative radiotherapy identifies evolution of multidimensional health problems and is indicative of quality of life. Eur J Cancer Care. 2014;23:401-412.

117. Cao $\mathrm{C}, \mathrm{Hu} \mathrm{Q}$, Chen $\mathrm{X}$. Intensity-modulated radiotherapy for elderly patients with nasopharyngeal carcinoma. Head Neck. 2018;40:590-595.

How to cite this article: Coca-Pelaz A, Halmos GB, Strojan $\mathrm{P}$, et al. The role of age in treatment-related adverse events in patients with head and neck cancer: A systematic review. Head \& Neck. 2019;41: 2410-2429. https://doi.org/10.1002/hed.25696 